\title{
Platelet-derived lysophosphatidic acid supports the progression of osteolytic bone metastases in breast cancer
}

\author{
Ahmed Boucharaba,1,2,3 Claire-Marie Serre,1,2,3 Sandra Grès, 4,5,6 \\ Jean Sébastien Saulnier-Blache,4,5,6 Jean-Claude Bordet,2,3,7 Julien Guglielmi, 1,2,3 \\ Philippe Clézardin, 1,2,3 and Olivier Peyruchaud1,2,3 \\ 1INSERM, U403, Lyon, France. 2Université Claude Bernard Lyon1, Lyon, France. ${ }^{3}$ Faculté de Médecine Laennec, Lyon, France.
4INSERM, U586, Toulouse, France. Institut Louis Bugnard, Toulouse, France. ${ }^{6}$ Université Paul Sabatier, Toulouse, France.
}

`EA3735, Laboratoire d'Hémobiologie, Lyon, France.

\begin{abstract}
The role of lysophosphatidic acid (LPA) in cancer is poorly understood. Here we provide evidence for a role of LPA in the progression of breast cancer bone metastases. $L P A$ receptors $L P A_{1}, L A_{2}$, and $L P A_{3}$ were expressed in human primary breast tumors and a series of human breast cancer cell lines. The inducible overexpression of $\mathrm{LPA}_{1}$ in MDA-BO2 breast cancer cells specifically sensitized these cells to the mitogenic action of LPA in vitro. In vivo, $\mathrm{LPA}_{1}$ overexpression in $\mathrm{MDA}-\mathrm{BO} 2$ cells enhanced the growth of subcutaneous tumor xenografts and promoted bone metastasis formation in mice by increasing both skeletal tumor growth and bone destruction. This suggested that endogenous LPA was produced in the tumor microenvironment. However, MDA-BO2 cells or transfectants did not produce LPA. Instead, they induced the release of LPA from activated platelets which, in turn, promoted tumor cell proliferation and the LPA $A_{1}$-dependent secretion of IL- 6 and IL-8, 2 potent bone resorption stimulators. Moreover, platelet-derived LPA deprivation in mice, achieved by treatment with the platelet antagonist Integrilin, inhibited the progression of bone metastases caused by parental and $\mathrm{LPA}_{1}$-overexpressing MDA-BO2 cells and reduced the progression of osteolytic lesions in mice bearing CHO- $\beta 3$ wt ovarian cancer cells. Overall, our data suggest that, at the bone metastatic site, tumor cells stimulate the production of LPA from activated platelets, which enhances both tumor growth and cytokinemediated bone destruction.
\end{abstract}

\section{Introduction}

Lysophosphatidic acid (LPA) is a naturally occurring bioactive lipid. Three distinct G protein-coupled receptors (GPCRs), namely $\mathrm{LPA}_{1}, \mathrm{LPA}_{2}$, and $\mathrm{LPA}_{3}$ (formerly called endothelial differentiation gene receptors 2,4 , and 7 , respectively), are specific receptors for LPA (1-3). Recently, a GPCR that is closely related to the purinergic GPCR family (GPR23/P2Y9) but shares no significant identity with other LPA receptors was suggested to be a fourth LPA receptor $\left(\mathrm{LPA}_{4}\right)$ (4). Additionally, the peroxisome proliferator-activated receptor $\gamma$, a transcriptional factor, was recently identified as an intracellular LPA receptor (5). Because the activation of the various $G$ proteins stimulates multiple signal transduction pathways, the cellular responses induced by LPA are remarkably diverse. Among these, LPA modulates proliferation, migration, and survival of many cell types (6).

Despite increasing data from in vitro studies, the pathophysiological role of LPA and its receptors is poorly understood. Their involvement in cancer is, however, emerging (7). LPA is pres-

Nonstandard abbreviations used: ATX, autotaxin; BS, total trabecular bone surface; $\mathrm{BV}$, bone volume; GPCR, G protein-coupled receptor; HA-LPA, HA-tagged $\mathrm{LPA}_{1}$; LPA, lysophosphatidic acid; $\mathrm{LPA}_{1}$, LPA receptor type 1 ; LPC, lysophosphatidic choline; lyso-PLD, lysophospholipase D; NCBI, National Center for Biotechnology Information; Oc.S, active-osteoclast resorption surface; PLB, phospholipase B; TB, tumor burden; TRAP, tartarate-resistant acid phosphatase; TV; tissue volume; $\mathrm{V}$, tumor volume; W, width.

Conflict of interest: The authors have declared that no conflict of interest exists.

Citation for this article: J. Clin. Invest. 114:1714-1725 (2004).

doi:10.1172/JCI200422123. ent at elevated levels in ascitic fluid and plasma from patients with ovarian, endometrial, and cervical cancers (7), and could therefore be a potential biomarker or indicator of response to therapy in gynecologic cancers $(8,9)$. In addition, ovarian cancers frequently show aberrant expression of $\mathrm{LPA}_{2}$ and $\mathrm{LPA}_{3}$ mRNAs compared with the normal ovarian epithelium (9-11).

Human MCF-7 and MDA-MB-435 breast cancer cells express $\mathrm{LPA}_{1}$ and $\mathrm{LPA}_{2}$ and respond to the mitogenic action of LPA in vitro (12). In addition, autotaxin (ATX), which possesses a lysophospholipase D (lyso-PLD) activity allowing the production of LPA from lysophosphatidic choline (LPC), is linked to the invasiveness of breast cancer cells in vitro (13).

Breast cancers frequently metastasize to bone (14). Bone metastases are associated with hypercalcemia due to bone destruction, intractable bone pain, and pathological fractures $(14,15)$. In bone metastasis, there is a vicious cycle wherein bone-residing tumor cells stimulate osteoclast-mediated bone resorption and bone-derived growth factors released from resorbed bone promote tumor growth (15-17). However, current treatments aimed to inhibit bone resorption (i.e., bisphosphonates) only delay the progression of osteolytic lesions in metastatic patients (18). Therefore, in addition to bone-derived growth factors, other endogenous sources of growth factors are probably involved in promoting skeletal tumor growth. In this respect, aggregation of human blood platelets upon thrombin activation is an important source of LPA $(19,20)$, and platelet aggregation plays a primordial role in the metastatic spreading of melanoma and Lewis lung carcinoma cells in bone (21) and 

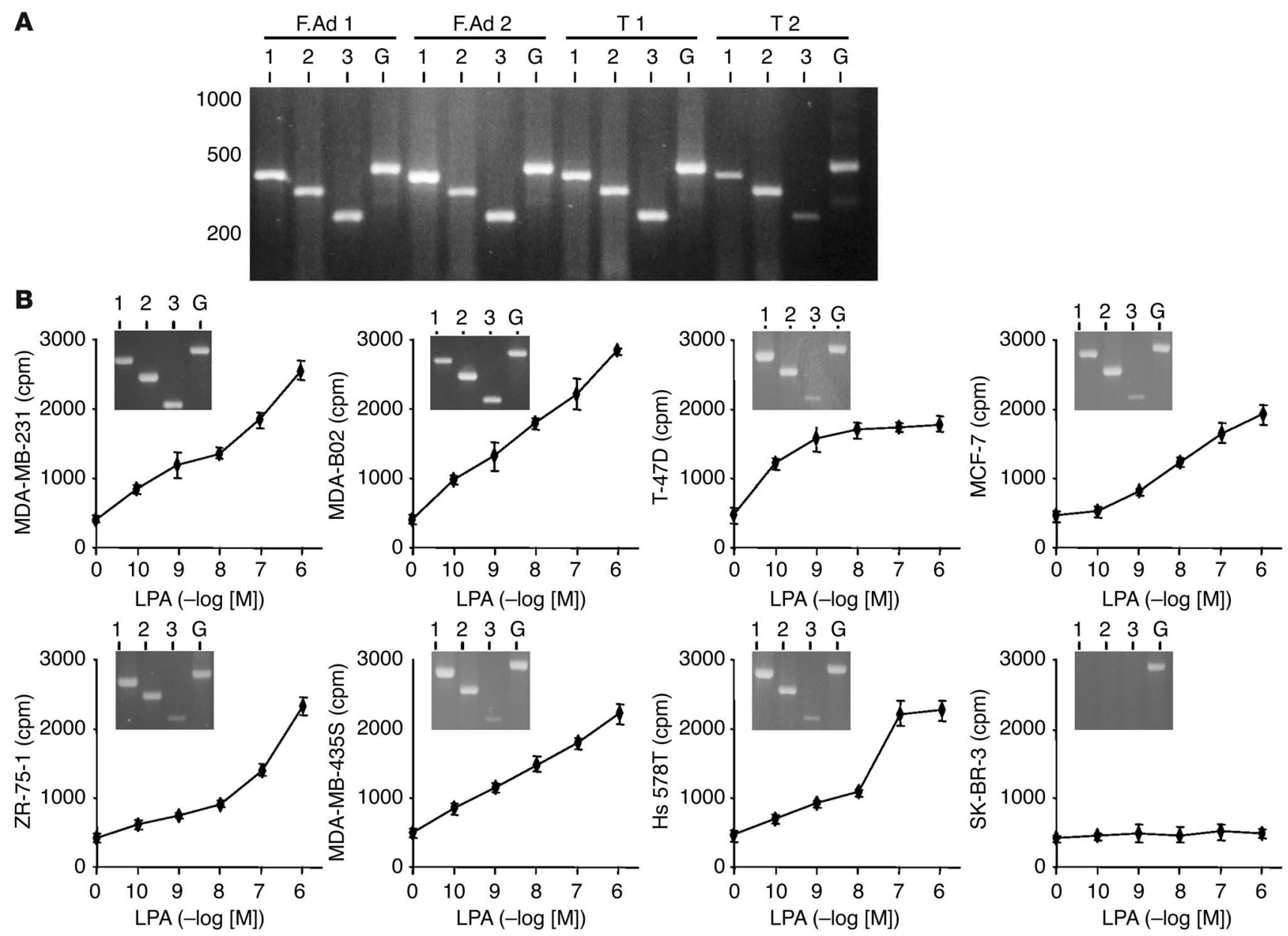

Figure 1

Expression of LPA receptors in breast cancer and mitogenic activity of LPA in breast cancer cell lines. (A) RT-PCR experiments using total RNA isolated from human primary tumors: fibroadenomas (F.Ad 1, F.Ad 2), ductal carcinomas (T 1, T 2). Expected size of amplification products for $\mathrm{LPA}_{1}(1), \mathrm{LPA}_{2}(2), \mathrm{LPA}_{3}(3)$, and GAPDH $(\mathrm{G})$ are $428,352,256$, and $470 \mathrm{bp}$, respectively. (B) Human breast cancer cell lines were stimulated with increasing concentrations of LPA and pulsed with $\left[{ }^{3} \mathrm{H}\right]$-thymidine. Cell proliferation was assessed after quantification of [ $\left.{ }^{3} \mathrm{H}\right]$-thymidine incorporation. Data are expressed in cpm as the mean \pm SD of 6 replicates and are representative of at least 3 separate experiments. Insets: RT-PCR amplification products for $\mathrm{LPA}_{1}, \mathrm{LPA}_{2}, \mathrm{LPA}$, and GAPDH using total RNA isolated from each indicated cell line.

lungs (22), respectively. Here we provide experimental evidence for a direct role of LPA in the progression of bone metastasis in breast cancer. We identify platelet-derived LPA as an endogenous source that, in the bone microenvironment, stimulates both tumor growth and bone destruction.

\section{Results}

The mitogenic action of LPA on breast cancer cells correlates with the presence of $L P A$ receptors. The biological activity of LPA is mediated through its interaction with specific cell-surface receptors (7). As exemplified here by RT-PCR, we detected mRNAs for $\mathrm{LPA}_{1}$, $\mathrm{LPA}_{2}$, and $\mathrm{LPA}_{3}$ receptors in human benign and neoplastic primary breast tumors (Figure 1A). Human MDA-MB-231, MDA-BO2, T-47D, MCF-7, ZR-75-1, Hs 578T, and MDA-MB-435S breast cancer cell lines also expressed all 3 LPA receptors, whereas SK-BR-3 breast cancer cells did not (Figure 1B, insets). Fang et al. (23) also reported the absence of LPA receptors in SK-BR-3 cells. LPA dose-dependently stimulated the proliferation of MDA-MB-231,
MDA-BO2, T-47D, MCF-7, ZR-75-1, Hs 578T, and MDA-MB-435S cells (Figure 1B), whereas SK-BR-3 cells did not respond to the mitogenic action of LPA (Figure 1B). These results suggested that LPA-dependent breast cancer cell proliferation was mediated through the activation of $L P A$ receptors $\mathrm{LPA}_{1}, \mathrm{LPA}_{2}$, and $\mathrm{LPA}_{3}$.

Overexpression of $L P A_{1}$ sensitizes buman $M D A-B O 2$ breast cancer cells to the mitogenic action of LPA in vitro. A broad range of LPA species can bind and activate $\mathrm{LPA}_{1}(24)$. Thus, to sensitize tumor cells to LPA stimulation, we developed an $\mathrm{LPA}_{1}$ receptor overexpression strategy. We used the tet-Off-regulated expression system in which the overexpression of $\mathrm{LPA}_{1}$ was achieved in the absence of the repressor (doxycycline). MDA-BO2 cells were chosen among the different breast cancer cell lines for transfection experiments with the bidirectional pBiL-HA-tagged $\mathrm{LPA}_{1}\left(\mathrm{pBiL}^{-H A}-\mathrm{LPA}_{1}\right)$ vector. In the absence of doxycycline, HA-LPA ${ }_{1}$ is overexpressed at the cell surface, whereas luciferase is produced in the cytoplasm. We selected 2 stable clones (MDA-BO2/HA-LPA 1 no. 3 and no. 79) on the basis of their specific and high expression of luciferase 

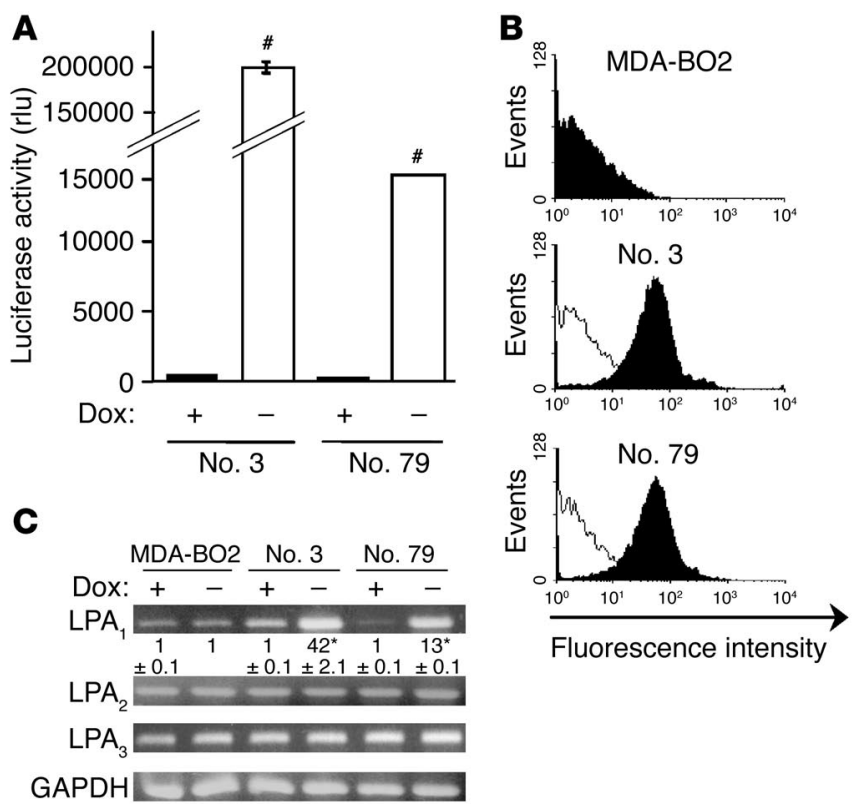

(Figure 2A) and HA-LPA 1 (Figure 2B). Real-time RT-PCR indicated that clones no. 3 and no. 79 had a 42- and 13-fold increase, respectively, in $\mathrm{LPA}_{1} \mathrm{mRNA}$ expression upon doxycycline withdrawal when compared with parental cells (Figure 2C). In addition, in the presence of the repressor, $\mathrm{LPA}_{1}$ mRNA expression levels in clones and parental MDA-BO2 cells were similar (Figure 2C). Finally, the cell transfection procedure as well as the presence or absence of doxycycline in the culture media did not alter the mRNA expression levels of $\mathrm{LPA}_{2}$ and $\mathrm{LPA}_{3}$ (Figure 2C).

In the presence of doxycycline, the proliferation of clones no. 3 and 79 in response to LPA stimulation was similar to that observed for parental MDA-BO2 cells (Figure 3A). Remarkably, in the absence of doxycycline, the overexpression of HA-LPA $\mathrm{H}_{1}$ enhanced the proliferation of clones no. 3 and 79 in response to LPA stimulation (Figure $3 \mathrm{~A}$ ). In contrast, the proliferation of clones no. 3 and 79 in response to PDGF, IGF-1, IGF-2, insulin, or EGF was similar in the presence or absence of doxycycline (Figure 3B). These results indicated that HA-LPA 1 overexpression specifically sensitized MDA-BO2 cells to the mitogenic action of LPA.

$L P A_{1}$ overexpression in $M D A-B O 2$ cells promotes skeletal tumor growth and breast cancer-induced bone destruction. To examine the role of LPA in the metastatic spreading of breast cancer cells in vivo, we

\section{Figure 3}

Effect of $\mathrm{LPA}_{1}$ overexpression on the mitogenic action of LPA on MDA-BO2 cells. (A) Parental MDA-BO2 cells (triangles) and transfected clones no. 3 (circles) and no. 79 (squares) were cultured in plain medium (open symbols) or medium supplemented with $100 \mathrm{ng} / \mathrm{ml}$ of doxycycline (filled symbols) and then treated as described in Figure 1B. Data are expressed in cpm as the mean \pm SD of 6 replicates and are representative of at least 3 separate experiments. ${ }^{\star \star} P<0.005$; ${ }^{\star} P<0.001$ untreated versus doxycycline-treated cell lines. (B) Cells were cultured in the absence or presence of doxycycline $(100 \mathrm{ng} / \mathrm{ml})$ and stimulated with LPA $(0.1 \mu \mathrm{M})$ or other indicated growth factors $(10 \mathrm{ng} / \mathrm{ml})$. Cell proliferation was measured as described above. Data are expressed as the mean \pm SD of 6 replicates and are representative of 3 separate experiments. ${ }^{*} P<0.001$ untreated versus doxycyclinetreated cell lines. Cont., control.

\section{Figure 2}

Characterization of MDA-BO2 clones stably transfected to conditionally overexpress $\mathrm{HA}-\mathrm{LPA}_{1}$. (A) Cells transfected with the bidirectional expression vector pBiL-HA-LPA 1 were plated with $(+)$ or without $(-)$ doxycycline (Dox). Two stable clones (nos. 3 and 79 ) were selected using luciferase activity measurement as an end point. Data are expressed in relative light units (rlu). ${ }^{\prime} P<0.0001$ for cells without doxycycline versus cells with doxycycline. (B) Detection of HA-LPA 1 cell surface expression in parental MDA-BO2 cells and in clones no. 3 and no. 79 by flow cytometry using the anti-HA monoclonal antibody. Black and white histograms refer to cells treated without and with doxycycline, respectively. The $y$ axis depicts the number of cells per channel (events), and the $x$ axis depicts the relative fluorescence intensity in arbitrary units (log scale). (C) LPA receptor mRNA expression in parental MDA-BO2 cells and in clones no. 3 and no. 79. Cells were cultured in the absence or presence of doxycycline before total RNA preparation. RT-PCR fragments were separated on a $2 \%$ agarose gel and then stained with ethidium bromide. Numbers below the top panel correspond to real-time PCR quantification data of the LPA 1 mRNA copy number for each clone compared with that of the parental MDA-BO2 cells cultured in the absence of doxycycline (mean $\pm \mathrm{SD}$; ${ }^{*} P<0.001$ ). No variation of mRNA expression was detected for $\mathrm{LPA}_{2}, \mathrm{LPA}_{3}$, or GAPDH in the presence or absence of doxycycline.

used an experimental model of bone metastasis caused by MDA$\mathrm{BO} 2$ cells that quite closely mimics the conditions likely to occur in naturally arising metastatic human breast cancers $(25,26)$. Thirty days after intravenous inoculation of each MDA-BO2/HA$\mathrm{LPA}_{1}$ clone in BALB/C nude mice, radiographic analyses revealed that animals fed with doxycycline-free water exhibited a dramatic increase in bone metastasis formation compared with doxycycline-fed animals and mice inoculated with parental cells (Figure 4A and Table 1). Overexpression of HA-LPA in clones no. 3 and 79 induced a 3 - and 2-fold increase, respectively, in the extent of

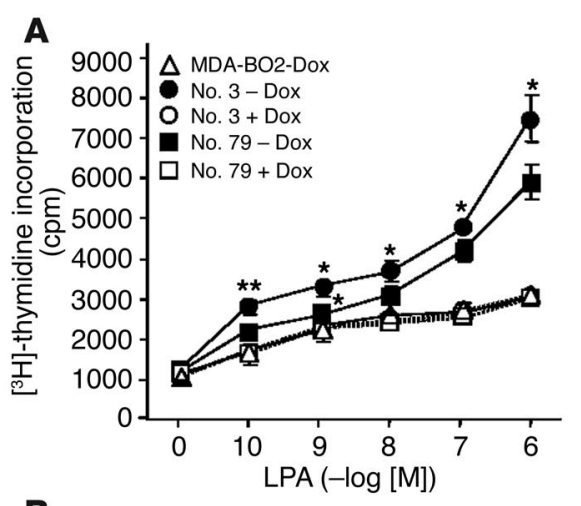

B

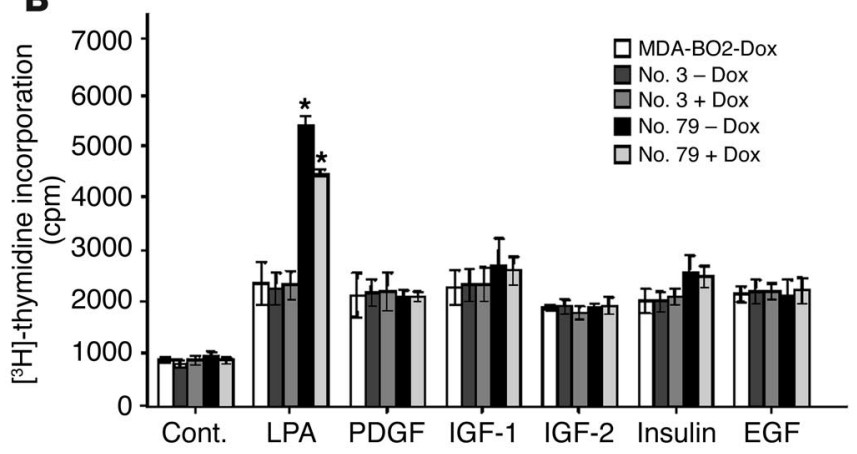


A

Dox:
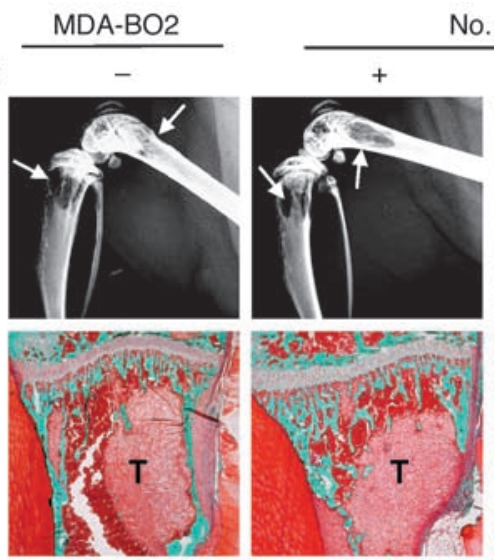

No. 3

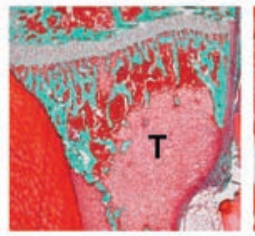

B

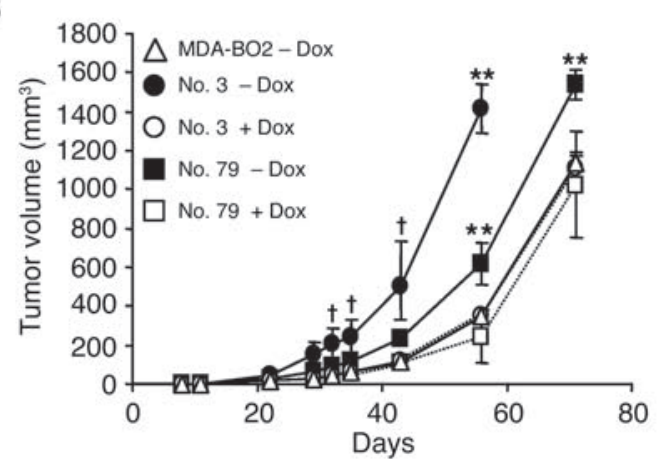

C
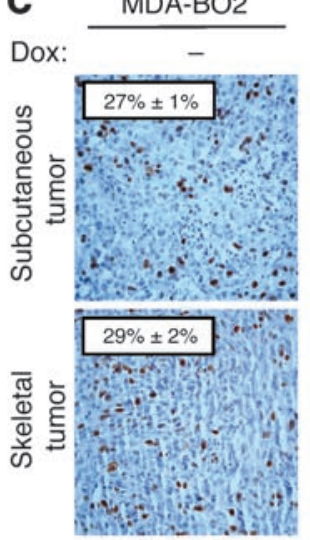

No. 3

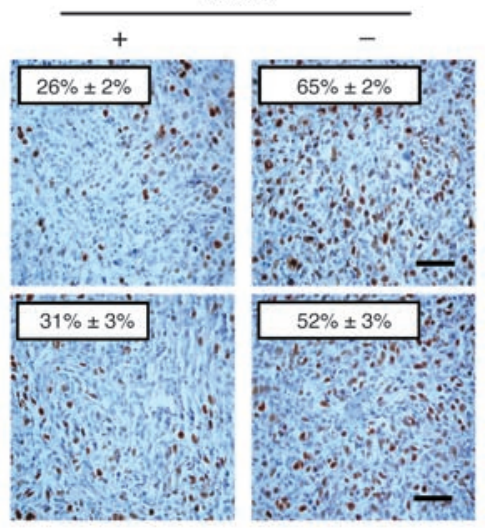

\section{Figure 4}

Effect of LPA 1 overexpression in MDA-BO2 cells on osteolytic lesions and on skeletal and subcutaneous tumor growth. (A) Animals fed without or with doxycycline were inoculated intravenously with MDA-BO2 or clone no. 3 cells. (Upper panels) Representative radiographs of hind limbs from mice bearing MDA-BO2 or clone no. 3 cells 30 days after tumor cell inoculation. In the absence of doxycycline, there was a marked increase in the extent of osteolytic lesions (arrows) in mice bearing clone no. 3 cells. (Lower panels) Representative bone histology of Goldner's trichrome-stained tibial metaphysis from metastatic animals. Bone is stained in green; bone marrow and tumor cells are stained red. Trabecular bone was completely destroyed and replaced by tumor cells $(T)$ in tibial metaphysis from untreated animals bearing clone no. 3 cells. Scale bar: $1 \mathrm{~mm}$. (B) Animals fed without (open symbols) or with (filled symbols) doxycycline were inoculated subcutaneously into the flank with MDA-BO2 (triangles), clone no. 3 (circles), or clone no. 79 (squares) cells. Tumors were measured at the indicated time points. $V$ (in $\mathrm{mm}^{3}$ ) is expressed as the mean $\pm \mathrm{SD}$ of 9 animals per group. ${ }^{\dagger} P<0.05$; ${ }^{* \star} P<0.005$ doxycycline-free versus doxycycline-fed tumor-bearing animals. (C) Subcutaneous (upper panels) and skeletal (lower panels) tumor tissue sections immunostained with an antibody against the nuclear $\mathrm{Ki}-67$ antigen. The mitotic index (numbers on each panel) was calculated as the percentage of nuclei positive for Ki-67. Results are the mean \pm SD of 6 independent tumor sections. $\#<0.0001$ doxycycline-free versus doxycycline-fed tumor-bearing animals. Scale bars: $100 \mu \mathrm{m}$.

osteolytic lesions (Table 1). Histological examination indicated

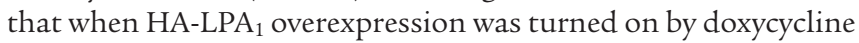
withdrawal, the cortical and cancellous bone were almost completely destroyed, and replaced by tumor cells that filled the bone marrow cavity and invaded adjacent tissues (Figure 4A). Histomorphometric analyses confirmed the results of radiographic analyses and showed that the overexpression of $\mathrm{HA}-\mathrm{LPA}_{1}$ by breast cancer cells resulted in a dramatic reduction of bone volume (BV) relative to tissue volume (TV) and increased skeletal tumor burden (TB) relative to TV (Table 1). We have previously shown that MDA-BO2 cells have a specific bone tissue location after tail vein inoculation into animals $(25,26)$. Histological examination of several organs from bone metastatic animals, including lungs, liver, and kidneys, confirmed previous observations for MDA$\mathrm{BO} 2$ cells and revealed that HA-LPA 1 overexpression by MDA$\mathrm{BO} 2$ cells did not affect the bone tropism of these tumor cells (data not shown). Overall, these results strongly suggested that cells overexpressing HA-LPA 1 were sensitized to an endogenous source of LPA produced in the bone microenvironment. We next determined whether this LPA-dependent effect was specific to the bone microenvironment.

$L P A_{1}$ overexpression enhances in vivo MDA-BO2 tumor growth. Tumor cells were implanted subcutaneously into nude mice. The growth rates of MDA-BO2 parental, clone no. 3 , and clone no. 79 tumor cells in doxycycline-fed animals were similar (Figure 4B). In contrast, the growth of tumor cells of clones no. 3 and no. 79 was markedly increased upon doxycycline withdrawal (Figure 4B). In agreement with growth curves, in situ immunodetection of the Ki-67 nuclear antigen in tumor sections showed a substantial increase in the proliferation of clone no. 3 overexpressing

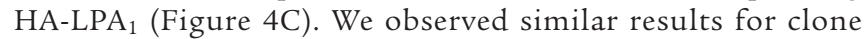
no. 79 (data not shown). In addition, subcutaneous and skeletal tumors overexpressing HA-LPA ${ }_{1}$ had a similar increase in proliferation, as judged by Ki-67 nuclear staining (Figure 4C). Therefore, the increase in in situ proliferation of breast cancer cells overexpressing HA-LPA ${ }_{1}$ in both subcutaneous and skeletal tumors was strongly suggestive of a local production of bioactive LPA, irrespective of the host tissue. 


\section{Table 1}

Quantification of osteolytic lesions and skeletal tumor burden in untreated and doxycycline-treated animals bearing parental MDA-B02 breast cancer cells or clone no. 3 and clone no. 79 cells overexpressing HA-LPA

\begin{tabular}{|c|c|c|c|c|c|c|}
\hline \multirow[t]{2}{*}{ Cell lines ${ }^{A}$} & \multicolumn{2}{|c|}{ Osteolytic lesions (mm²) } & \multicolumn{2}{|c|}{ BV/TV (\%) } & \multicolumn{2}{|c|}{ TB/TV (\%) } \\
\hline & $+\operatorname{Dox}(n)$ & -Dox (n) & $+\operatorname{Dox}(n)$ & $-\operatorname{Dox}(n)$ & $+\operatorname{Dox}(n)$ & $-\operatorname{Dox}(n)$ \\
\hline MDA-B02 & $6.3 \pm 1.5(9)$ & $5.7 \pm 1.1(6)$ & $5.8 \pm 0.3(9)$ & $5.7 \pm 1.5(6)$ & $32 \pm 4.3(9)$ & $33 \pm 3.3(6)$ \\
\hline MDA-B02/HA-LPA 1 no. 3 & $6.2 \pm 1.0(6)$ & $18.6 \pm 2.7^{A}(9)$ & $5.8 \pm 0.4(6)$ & $0.03 \pm 0.05^{A}(9)$ & $30 \pm 3.4(6)$ & $98 \pm 2.0^{A}(9)$ \\
\hline MDA-B02/HA-LPA 1 no. 79 & $5.4 \pm 0.3(6)$ & $10.1 \pm 1.0^{A}(6)$ & $5.8 \pm 0.4(6)$ & $2.2 \pm 1.5^{\mathrm{A}}(6)$ & $34 \pm 6.1(6)$ & $53 \pm 8.4^{A}(6)$ \\
\hline
\end{tabular}

Data are the mean \pm SD of 2 separate experiments for each cell line using $n$ animals. ${ }^{A} P<0.001$ using unpaired Student's $t$ test when comparing animals fed with and without doxycycline (Dox). ${ }^{A}$ MDA-BO2, parental human breast cancer cell line; MDA-BO2/HA-LPA 1 no. 3 and no. 79 , clones overexpressing $\mathrm{HA}_{\mathrm{LPA}}$ at the cell surface upon doxycycline withdrawal.

MDA-BO2 cells do not produce LPA or express ATX. To identify the potential sources of LPA, we first speculated that tumor cells themselves might produce LPA, which could secondarily act as an autocrine factor in vivo. However, using a radioenzymatic assay, we found that MDA-BO2 parental cells and clone no. 3 cells (clone no. 79 cells were not tested) did not produce detectable amount of LPA (less than $0.2 \mathrm{pmol}$ ) in their culture media (Figure 5A). These results were in agreement with in vitro cell proliferation experiments showing that cells overexpressing $\mathrm{HA}-\mathrm{LPA}_{1}$ grew at the same rate as doxycycline-treated cells when cultured in the control medium (Figure 3A). In addition, MDA-BO2 parental and clone no. 3 cells did not produce detectable amounts of lyso-PLD activity in their culture media (Figure 5B). The absence of ATX mRNA in our cell lines was confirmed by RT-PCR experiments (data not shown). These results strongly suggested that our breast cancer cell lines were unlikely to produce LPA in vivo.

$M D A-B O 2$ cells induce platelet aggregation and the subsequent release of LPA from activated platelets. Platelets present in the blood circulation are an important source of LPA that is released during throm- bin-induced platelet aggregation $(19,20)$. In addition, platelet aggregation induced by tumor cells plays an important role during tumor cell dissemination $(21,22,27)$. We therefore studied the platelet-aggregating activity of our breast cancer cell lines (clone no. 79 cells were not tested). MDA-MB-231, MDA-BO2 parental, or HA-LPA 1 overexpressing cells (clone no. 3 ) did induce platelet aggregation (Figure 6A) and stimulated the release of LPA from activated platelets (Table 2). Supernatants of tumor cell-induced platelet aggregation promoted the proliferation of clone no. 3 cells (Figure 6B). Moreover, clone no. 3 cells were sensitized to this mitogenic action in a doxycycline-dependent manner, which was completely abrogated in the presence of phospholipase B (PLB, an LPA-degrading enzyme) (Figure 6B). These results indicated that LPA released from activated platelets upon stimulation by tumor cells was bioactive and promoted breast cancer cell proliferation in vitro.

Platelet-derived LPA deprivation in animals blocks the progression of bone metastases. Pharmacological inhibition of platelet aggregation using a specific integrin $\alpha \operatorname{IIb} \beta 3$ antagonist prevents the early entry of B16 melanoma cells into bone (21). To examine

\section{Figure 5}

Production of LPA and ATX by MDA-BO2 breast cancer cells. Cell culture media were collected for each indicated cell line placed in the absence or presence of doxycycline (100 $\mathrm{ng} / \mathrm{ml}$ ). (A) Detection of LPA. The production of phosphatidic acid (PA) was due to the transfer of $\left[{ }^{14} \mathrm{C}\right]$ fatty acyl chain (FA) onto LPA present in the reaction mixture assay. Experiments were carried out in duplicate for each cell line. Purified LPA (50, 100, and 200 pmol) was used as a positive control. DMEM (Cont.) was used as a negative control. (B) Measurement of ATX/lyso-PLD activity. $\left[{ }^{14} \mathrm{C}\right]-\mathrm{LPC}$ was used as the substrate of ATX/lyso-PLD to produce $\left[{ }^{14} \mathrm{C}\right]$-LPA. Experiments were carried out in duplicate using culture media from the cell lines described above. Note that MDA-MB-231, MDA-BO2, clone no. 3, and clone no. 79 cell lines did not produce LPA or express ATX.

\section{A}

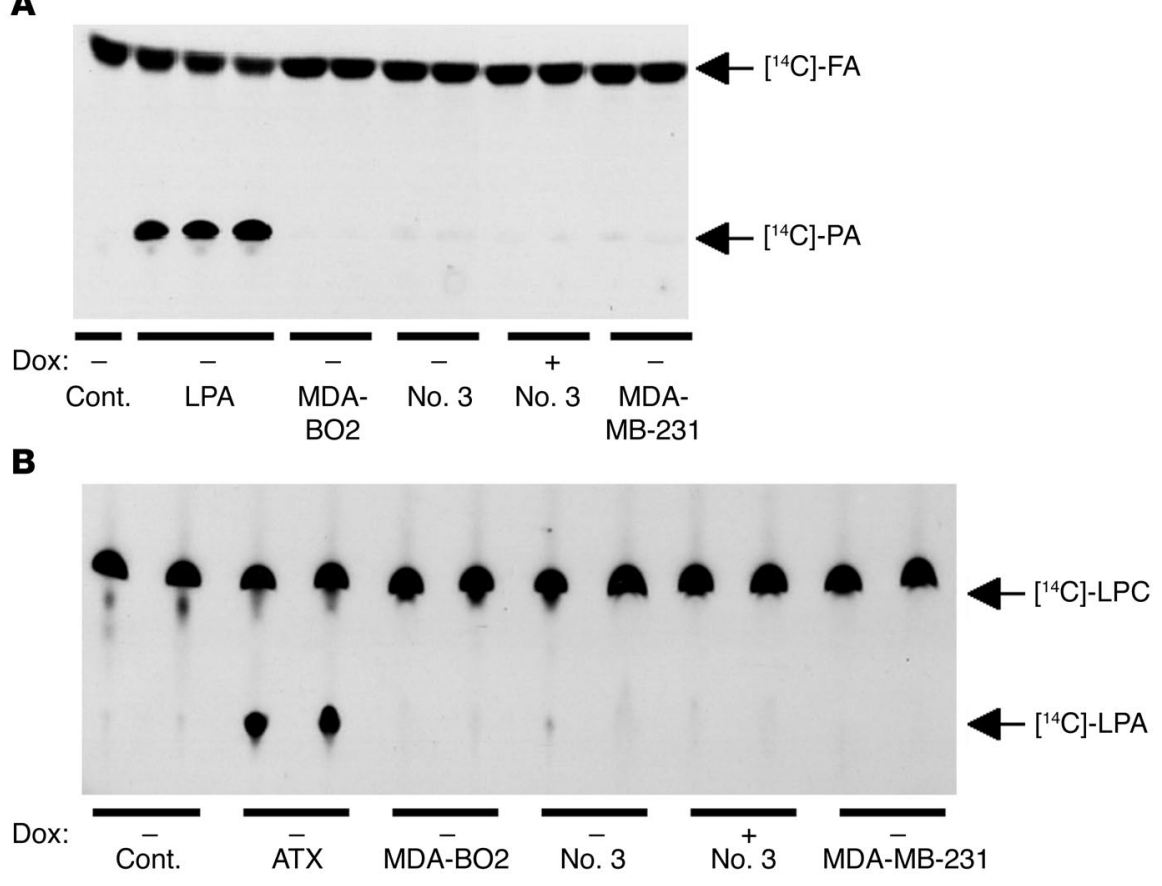



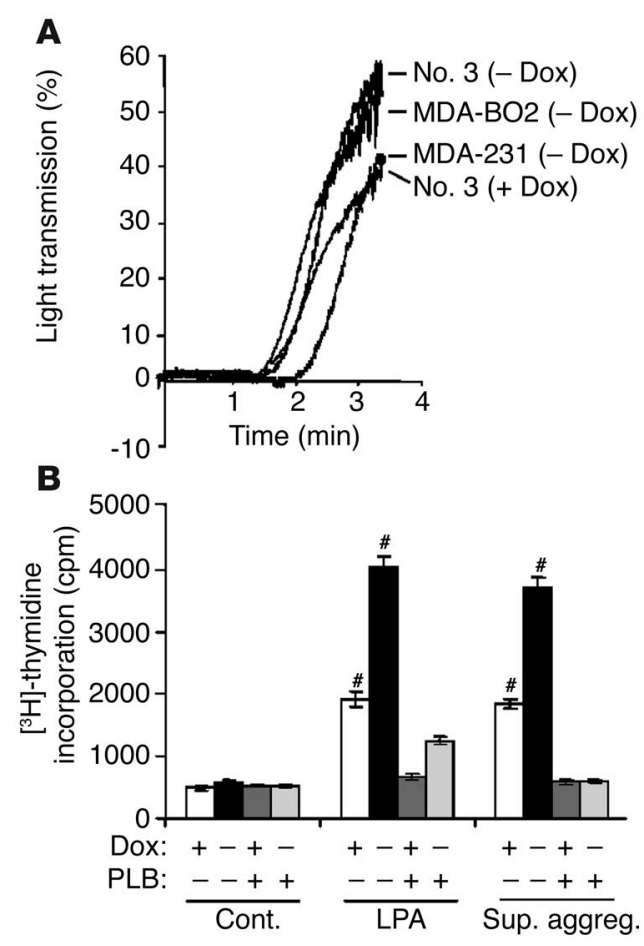

the role of platelet aggregation during the progression of established bone metastases, animals bearing MDA-BO2 parental or HA-LPA 1 overexpressing clone no. 3 cells (clone no. 79 cells were not tested) were treated with the integrin $\alpha \operatorname{IIb} \beta 3$ antagonist Integrilin, starting at day 14 after tumor cell inoculation. As expected, Integrilin treatment of metastatic animals induced a severe thrombocytopenia ( $30 \pm 9$ platelets/nl compared with $210 \pm 20$ platelets/nl in untreated metastatic animals; data are expressed as mean $\pm \mathrm{SD}$ ). This thrombocytopenia was concomitant with a drastic decrease (70\% reduction) of circulating levels of LPA in Integrilin-treated metastatic mice compared with those observed in untreated metastatic animals (Table 3 ). These findings strongly suggested that blood platelets were the endogenous source of LPA in metastatic animals. The LPA deprivation upon Integrilin treatment of MDA-BO2 metastatic animals was associated with a $50 \%$ reduction in the extent of osteolytic lesions compared with that observed in vehicle-treated animals (Figure 7, A and B). Moreover, the dramatic increase of bone destruction observed in animals bearing cells overexpressing HA-LPA ${ }_{1}$ was completely abolished upon Integrilin treatment (Figure 7, A and B). This inhibition was also associated with a substantial decrease of skeletal tumor burden as judged by histomorphometric analysis (data not shown).

To determine whether the role of LPA was restricted to breast cancer bone metastasis, similar experiments were conducted with CHO- $\beta 3$ wt cancer cells, which we have previously shown to induce bone metastasis in animals (26). As exemplified by RT-PCR using CHO-based primers, we detected $\mathrm{LPA}_{1} \mathrm{mRNA}$, but not $\mathrm{LPA}_{2}$ nor $\mathrm{LPA}_{3}$ mRNAs, in our CHO- $\beta 3$ wt cells (Figure $8 \mathrm{~A}$, inset). In agreement with the presence of active $\mathrm{LPA}_{1}$, the proliferation of these cells was stimulated in response to increasing concentrations of LPA, which was abrogated in the presence of PLB (Figure 8A). CHO$\beta 3 w t$ cells also induced platelet aggregation in vitro (Figure $8 \mathrm{~B}$ ). Thus, Integrilin treatment of metastatic animals might also affect

\section{Figure 6}

Effect of breast tumor cells on platelet aggregation and the release of LPA from activated platelets. (A) Indicated tumor cells previously cultured in the absence or presence of doxycycline were added to washed human platelets under stirring conditions. Platelet aggregation was recorded over the time as the percentage of light transmission. (B) Clone no. 3 cells were plated without or with doxycycline and stimulated with DMEM, LPA (10-7 M) or MDA-BO2-induced platelet aggregation supernatants (Sup. aggreg.), in the presence or absence of PLB. Cell proliferation was measured as described in the legend of Figure 3. Data are expressed as the mean \pm SD of 6 replicates and are representative of 3 separate experiments. $\# P<0.0001$, stimulated versus control cells.

the progression of bone metastases caused by CHO- $\beta 3$ wt cells. Indeed, we found that an 11-day treatment of metastatic animals with Integrilin, starting at day 10 after cell inoculation, inhibited by 3 -fold the extent of bone metastases caused by $\mathrm{CHO}-\beta 3 \mathrm{wt}$ cells (Figure 8C). Overall, these results obtained with 2 different animal models of bone metastasis strongly suggested that blood platelets were the main endogenous source of LPA. Bone-residing tumor cells stimulated the release of LPA by inducing platelet aggregation, which, in turn, promoted the proliferation of tumor cells. The reason that $\mathrm{LPA}_{1}$ overexpression in MDA-BO2 cells was also associated with a higher bone destruction was, however, unclear.

$L P A_{1}$ overexpression in MDA-BO2 cells increases the recruitment of osteoclasts at the bone metastatic site. Tumor cells do not directly destroy bone (21). Instead they mediate the recruitment and stimulate the activity of osteoclasts at the bone metastatic site (15-17). Histological examination showed that the recruitment of osteoclasts on trabecular bone located at the bone/tumor cell interface was increased in metastatic long bones from doxycycline-free water fed animals bearing HA-LPA 1 overexpressing MDA-BO2 cells (clone no. 3 and clone no. 79) compared with those from doxycycline-fed animals and from mice bearing parental cells (Figure 9A). Histomorphometric quantification revealed that $\mathrm{HA}-\mathrm{LPA}_{1}$ overexpression in clones no. 3 and no. 79 induced a 3.5- and 2-fold increase, respectively, in active-osteoclast resorption surface (Oc.S) per trabecular bone surface (BS) (Figure 9B). This observation strongly suggested that the increase in the extent of osteolytic lesions observed in animals bearing cells overexpressing HA-LPA 1 was due to increased osteoclast bone resorption activity.

$L P A_{1}$ overexpression enhances the LPA-dependent production of $I L-6$ and $I L-8$ by MDA-BO2 cells. Fang et al. have recently shown that LPA stimulates the production of IL- 6 and IL- 8 by ovarian and

\section{Table 2}

Quantification of LPA in the supernatant of platelet aggregates

\begin{tabular}{|c|c|}
\hline Platelet stimulating factor & LPA (nM) \\
\hline None & $9 \pm 8.2$ \\
\hline Thrombin $(0.05 \mathrm{U} / \mathrm{ml})$ & $101 \pm 72.6$ \\
\hline MDA-MB-231 (-Dox) & $97 \pm 39.1$ \\
\hline MDA-B02 (-Dox) & $124 \pm 30.2$ \\
\hline MDA-B02/HA-LPA 1 no. 3 (+Dox) & $144 \pm 25.1$ \\
\hline MDA-B02/HA-LPA ${ }_{1}$ no. 3 (-Dox) & $145 \pm 18.5$ \\
\hline
\end{tabular}

Results were obtained from 3-4 separate donors and are expressed as the mean $\pm S D$. 
Table 3

Quantification of LPA in the plasma of metastatic animals

$\begin{array}{llc}\text { Animals } & \boldsymbol{n} & \text { LPA }(\mathbf{n M}) \\ \text { MDA-B02 cells + vehicle } & 6 & 257.6 \pm 63.3 \\ \text { MDA-B02 cells + Integrilin } & 9 & 76.3 \pm 7.37 \mathrm{~A}\end{array}$

Animals bearing MDA-BO2 cells were treated with the anti-platelet agent Integrilin or vehicle every 3 days from day 14 to day 30 , at which time animals were sacrificed and circulating levels of LPA in the plasma were measured. Results are expressed as the mean \pm SE from $n$ animals. ${ }^{A} P<0.01$ using unpaired Student's $t$ test compared with animals not treated with Integrilin.

breast cancer cells (23). Cytokines are important modulators of osteoclast functions (28), and the secretion of IL- 6 and IL-8 by tumor cells stimulates osteoclast-mediated bone destruction in vivo $(29,30)$. Here, LPA stimulated production of both IL-6 (Figure 10A) and IL-8 (Figure 10B) by MDA-BO2 cells, and this cytokine production was markedly increased when clone no. 3 cells overexpressed HA-LPA . Similarly, the supernatant of tumor cell-induced platelet aggregation promoted the production of IL- 6 and IL-8 in an LPA-dependent manner (Figure 10, A and B). Thus, in addition to its direct mitogenic effect on tumor cells, LPA indirectly stimulated bone destruction through the increased production of IL- 6 and IL- 8 by breast cancer cells. Therefore, the increased osteolytic lesions in animals inoculated with tumor cells overexpressing $\mathrm{LPA}_{1}$ might be the result of enhanced LPA-dependent tumor cell proliferation, increased osteoclastogenesis mediated by IL- 6 and IL-8, or, more likely, a combination of both mechanisms acting in concert.

\section{Discussion}

The role for LPA in ovarian, endometrial, cervical, melanoma, and prostate cancers is currently emerging (7). Despite studies reporting the effects of LPA on breast cancer cells in vitro $(12,23,31,32)$, the role of LPA in breast cancer in vivo was not known. In the present study, we demonstrated that LPA promoted breast cancer progression in vivo. This contention was first supported by the fact that the mitogenic activity of LPA on a series of human breast cancer cell lines correlated with the expression of LPA receptors. We also observed that overexpression of $\mathrm{LPA}_{1}$ specifically sensitized MDA-BO2 breast cancer cells in culture to the mitogenic action of LPA. Secondly, the growth of subcutaneous breast tumor xenografts or skeletal breast tumor metastases was markedly increased when $\mathrm{LPA}_{1}$ overexpression in MDA-BO2 breast cancer cells was turned on by doxycycline withdrawal. Moreover, the mitotic index of MDA-BO2 cells in situ was also increased when $\mathrm{LPA}_{1}$ overexpression was turned on. These results do not preclude the possibility that $\mathrm{LPA}_{2}$ and $\mathrm{LPA}_{3}$ receptors may also

\section{Figure 7}

Effect of in vivo inhibition of platelet aggregation on the LPA-dependent progression of breast cancer bone metastases. (A) Representative radiographs at day 30 of hind limbs from doxycycline-free fed mice bearing MDA-BO2 or clone no. 3 cells that were treated with Integrilin or vehicle from day 14 to day 30. (B) Quantification of osteolytic lesion areas on radiographs in Integrilin-treated $(+)$ and vehicle-treated (-) metastatic animals. Values are the mean \pm SE of $6-9$ animals per group. ${ }^{\# \#} P<0.01 ;{ }^{*} P<0.001$, Integrilin-treated versus vehicle-treated animals. play a role in breast cancer progression in vivo. However, because the overexpression of $\mathrm{LPA}_{1}$ did not induce any modification in the expression levels of $\mathrm{LPA}_{2}$ and $\mathrm{LPA}_{3}$ in MDA-BO2 cells, our results strongly suggested that the increased in vivo growth of MDA-BO2 cells upon doxycycline withdrawal was directly related to the overexpression of $\mathrm{LPA}_{1}$. Local production of bioactive LPA in the tumor microenvironment in vivo should therefore support $\mathrm{LPA}_{1}$-dependent breast tumor cell proliferation.

It has been previously reported that MDA-MB-231 breast cancer cells do not directly produce LPA (13). However, ATX in MDA-MB-231 and MDA-MB-435S breast cancer cells can induce the production of bioactive LPA, which in turn stimulates cell migration, invasion, and proliferation $(13,32,33)$. In the present study, MDA-BO2 cells and transfectants did not directly produce LPA or express ATX.

We therefore focused our attention on human blood platelets. Several factors suggested that platelets could locally produce bioactive LPA in vivo in the tumor bed. First, thrombin-activated platelets (19) and lyso-PLDs (20) are major sources of LPA in the serum. Second, platelets play a major role in the metastatic dissemination of tumor cells in vivo $(27,34,35)$, and, more recently, platelet aggregation was shown to be essential for successful formation of B16 melanoma bone metastases in animals (21). Third, because of the leaky vasculature of angiogenic tumors (36), platelets are in contact with tumor cells and are therefore able to secrete multiple factors upon activation (37). Fourth, MDA-MB-231 breast cancer cells (as well as other tumor cell lines) interact with platelets and stimulate platelet aggregation in vitro (38), suggesting that the platelet-aggregating activity of breast cancer cells might induce the release of LPA from activated platelets. In agreement with the latter findings (38), we observed here that our MDA-BO2
A
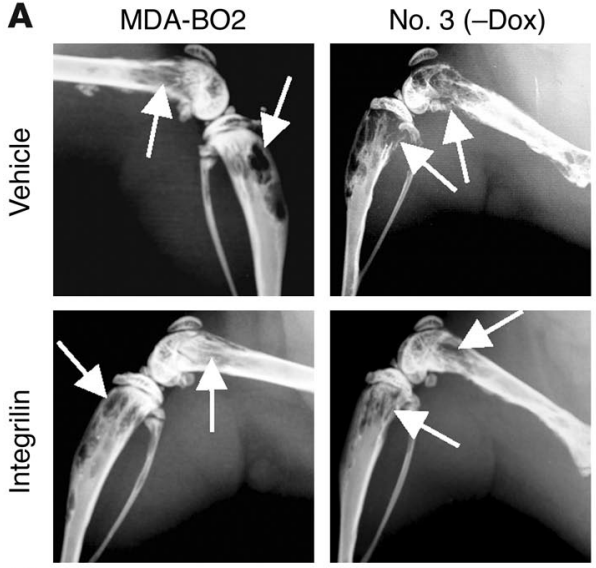

B

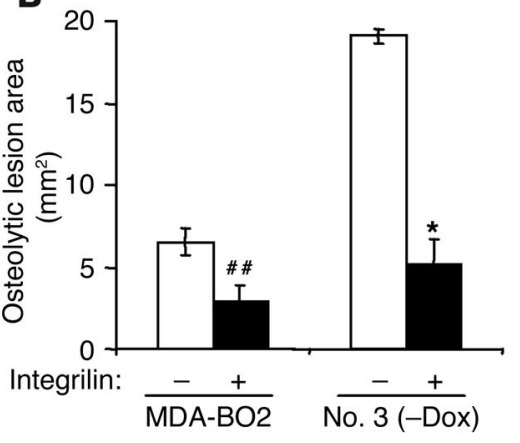



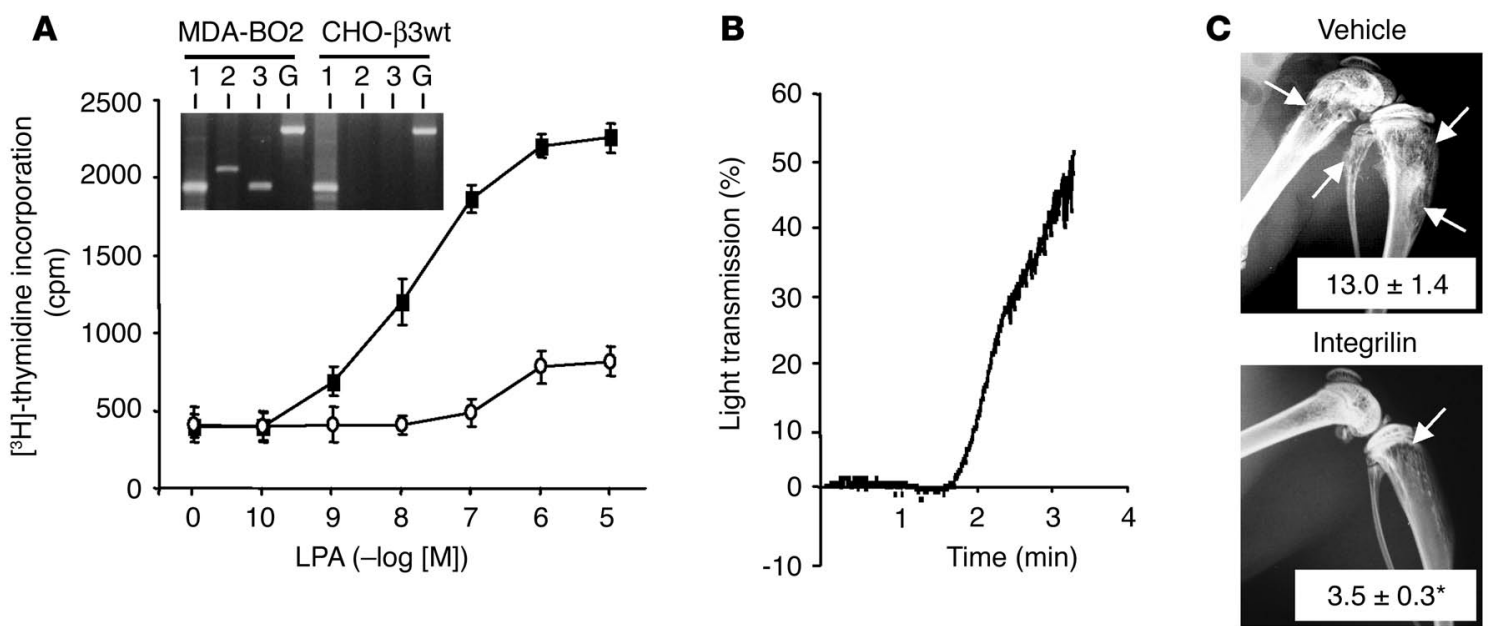

\section{Figure 8}

Mitogenic effect of LPA on CHO- $\beta 3$ wt cells in vitro and effect of in vivo inhibition of platelet aggregation on the progression of $\mathrm{CHO}-\beta 3 w t$ bone metastases. (A) Cell proliferation assay: CHO- $\beta 3 w t$ cells were incubated with increasing concentrations of LPA in the absence (filled squares) or presence (open circles) of PLB. Cell proliferation was assessed as described in Figure 1B. Data are expressed in cpm as the mean \pm SD of 6 replicates and are representative of at least 3 separate experiments. Inset: RT-PCR amplification products for $\mathrm{LPA}_{1}, \mathrm{LPA}_{2}, \mathrm{LPA}_{3}$, and GAPDH using MDA-BO2 or CHO- $\beta 3$ wt total RNAs. Expected size of amplification products for LPA ${ }_{1}, \mathrm{LPA}_{2}$, LPA $\mathrm{L}_{3}$, and GAPDH are 192, 282, 182, and 470 bp, respectively. (B) $\mathrm{CHO}-\beta 3 w t$ cell stimulation of platelet aggregation was carried out as described in Figure 6 . (C) Bone metastasis experiment. Representative radiographs at day 21 of hind limbs from mice bearing CHO- $\beta 3$ wt cells treated with Integrilin or vehicle from day 10 to day 21. Osteolytic lesions are indicated by arrows. Data represent the mean \pm SE of osteolytic lesion areas, expressed in $\mathrm{mm}^{2}$, of 8-10 animals per group. ${ }^{*} P<0.001$ Integrilin-treated versus vehicle-treated animals.

parental and transfected breast cancer cell lines strongly stimulated platelet aggregation and the subsequent release of LPA from activated platelets. In addition, platelet-derived LPA stimulated in vitro the proliferation of parental MDA-BO2 cells, and this activity was further increased upon $\mathrm{LPA}_{1}$ overexpression. In vivo, a highly specific platelet aggregation inhibitor (Integrilin) inhibited by $50 \%$ the extent of bone metastases caused by MDA$\mathrm{BO} 2$ cells and markedly blocked the progression of osteolytic lesions and skeletal tumor burden in animals bearing $\mathrm{LPA}_{1}$-overexpressing cells. Moreover, this observation was not restricted to our MDA-BO2 breast cancer bone metastasis model since Integrilin also inhibited the progression of bone metastases caused by $\mathrm{CHO}-\beta 3 \mathrm{wt}$ ovarian cancer cells. Thus, it is most likely that platelet-derived LPA promotes breast cancer growth in vivo. The experiments presented here provide evidence of LPA-dependent tumor promotion in MDA-BO2 and CHO- $\beta 3$ wt models. It is therefore important to test additional tumors to determine whether paracrine signaling by LPA is a general mechanism of metastatic tumor growth.

Because subcutaneous and skeletal MDA-BO2 breast tumors are highly vascularized (39), these data strongly support the idea that platelets from the blood stream come into contact with the tumor bed in vivo, and then aggregate and secrete LPA, which stimulates the proliferation of breast cancer cells. Interestingly, compared with human serum, mouse serum contains relatively little LPA (8); more importantly, in contrast to human platelets, mouse platelets do not aggregate in response to LPA in vitro (40). Therefore, we anticipate that the contribution of LPA to the progression of the bone metastatic disease in patients could be even more important than that observed here in animals.

Besides the fact that LPA and its receptor $\mathrm{LPA}_{1}$ promoted the growth of primary or metastatic breast tumors, we also showed evi- dence indicating that LPA could indirectly contribute to the bone destruction associated with MDA-BO2 skeletal metastases. LPA was recently shown to stimulate the production of IL- 6 and IL-8 by ovarian and breast cancer cells (23). Tumor cells do not directly destroy bone (21). Instead, IL- 6 and IL- 8 produced by breast cancer cells stimulate osteoclast-mediated bone resorption (41). We showed here that platelet-derived LPA, as well as purified LPA, stimulated the secretion of these cytokines by MDA-BO2 breast cancer cells. In addition, production of IL- 6 and IL- 8 was markedly increased when tumor cells overexpressed $\mathrm{LPA}_{1}$. It is, therefore, conceivable that beyond its tumor growth-promoting effect, LPA indirectly stimulates osteoclast-mediated bone resorption. Thus, in addition to the vicious cycle related to the direct reciprocal interaction between breast cancer cells and osteoclast-mediated bone resorption $(15,16)$, we propose that there exists an LPA-dependent cycle wherein bone-residing tumor cells stimulate LPA production by platelets, which in turn enhances tumor growth and cytokine-mediated bone resorption (Figure 11).

Although a role for LPA in cancer was emerging, there was a paucity of experimental evidence to support it. This study is, to the best of our knowledge, the first to demonstrate a role for LPA and its receptor $\mathrm{LPA}_{1}$ in the growth of breast cancer bone metastasis.

\section{Methods}

Cell lines and transfection. Hs 578T, MCF-7, MDA-MB-231, MDA-MB-435S, SK-BR-3, T-47D, and ZR-75-1 cells were obtained from the American Type Culture Collection. Characteristics of CHO- $\beta 3 w t, M D A-M B-231 / \mathrm{BO} 2$ (MDA-BO2), and tet-Off-expressing MDA-BO2 breast cancer cells were described elsewhere $(26,39)$. The cDNA encoding the entire human $\mathrm{LPA}_{1}$ and the antigenic epitope tag (HA) fused at the $\mathrm{NH}_{2}$ terminus of $\mathrm{LPA}_{1}$ was amplified by PCR using the vector PEDG-2 (42) as a template and 2 oligonucleotide primers (5'-CCGCTAGCATGTACCCATACGAC- 
GTCCCAGACTACGCTATGGCTGCCATCTCTACT-3' [HA-edg2N] and 5'-CGCAAGCTTCTAAACCACAGAGTGGTCATTGC-3' [Stop-edg2]). The bidirectional vector PBiL/HA-LPA1 was constructed by inserting into the pBiL plasmid (Clontech) the NheI/HindIII PCR fragment encoding the HA-LPA 1 sequence. MDA-MB-231/BO2-tet-Off cells were cotransfected with $\mathrm{pBiL} / \mathrm{HA}-\mathrm{LPA}_{1}$ together with a vector conferring puromycin resistance (pPur; BD Biosciences - Clontech). Selection of the clones was obtained after growing the cells for 2 weeks in the presence of puromycin $(2 \mu \mathrm{g} / \mathrm{ml})$. Luciferase induction upon doxycycline withdrawal was used to select inducible clones among stable transfectants. Two HA-LPA ${ }_{1}$-inducible transfectants (clones no. 3 and 79) were used in the present study. Cell lines and inducible transfectants, with the exception of SK-BR-3 cells, were routinely cultured in DMEM/NUT.MIX f-12 W/GLUT-1 medium (Life Technologies) supplemented with 10\% (v/v) fetal bovine serum (Bio-Media) and $1 \%$ penicillin/streptomycin (Life Technologies) at $37^{\circ} \mathrm{C}$ in a $5 \% \mathrm{CO}_{2}$ incubator. SK-BR-3 cells were grown in complete McCoy's 5 a medium (Life Technologies).

Animal studies. All procedures were performed on female BALB/c $\mathrm{nu} / \mathrm{nu}$ mice of 4 weeks of age (Charles River). Studies involving animals, including housing and care, method of euthanasia, and experimental protocols, were conducted in accordance with a code of practice established by the Experimentation Review Board from the Laennec School of Medicine, Lyon, France. These studies were routinely inspected by the Attending Veterinarian to ensure continued compliance with the proposed protocols. Two days before tumor cell inoculation, animals were provided with drinking water containing $5 \%(\mathrm{w} / \mathrm{v})$ sucrose supplemented with or without doxycycline $(1 \mathrm{mg} / \mathrm{ml})$.

Bone metastasis experiments in animals were conducted as previously described $(26,39)$. Briefly, doxycycline-treated or untreated MDA-BO2 transfectants $\left(5 \times 10^{5}\right.$ cells in $100 \mu l$ of phosphate-buffered saline) were inoculated into the tail vein of anesthetized nude mice treated with doxycycline or left untreated, respectively. Alternatively, CHO- $\beta 3 \mathrm{wt}$ cells $\left(10^{6}\right.$ cells in $100 \mu \mathrm{l}$ of phosphate-buffered saline) were inoculated intravenously into animals. Metastatic animals were also treated every 3 days with the anti-platelet agent eptifibatide (Integrilin; Schering-Plough) by intraperitoneal injection $(0.5 \mathrm{mg} / \mathrm{kg} /$ day $)$. Integrilin treatment began at the time osteolytic lesions were radiographically detectable in animals (at day 10 and day 14 for CHO- $\beta 3 w t$ and MDA-BO2 cells, respectively). Radiographs (MIN-R2000 films; Kodak) were then taken 21 (CHO- $\beta 3 \mathrm{wt}$ cells) or 30 days (MDA-BO2 cells and transfectants) after tumor cell inoculation using a cabinet X-ray system (MX-20; Faxitron X-ray Corporation), and bone metastases were enumerated on each radiograph. The area of osteolytic lesions was measured using the computerized image analysis system Visiolab 2000 (Biocom), and results were expressed in square millimeters.

For tumor xenograft experiments, MDA-BO2 transfectants previously cultured in the presence of doxycycline to block the overexpression of HA-LPA 1 were inoculated subcutaneously $\left(10^{6}\right.$ cells in $100 \mu$ l of phosphate-
A
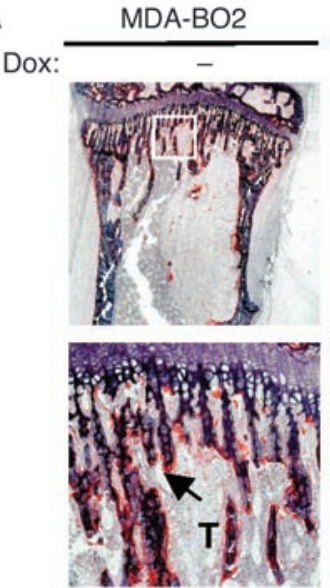

B

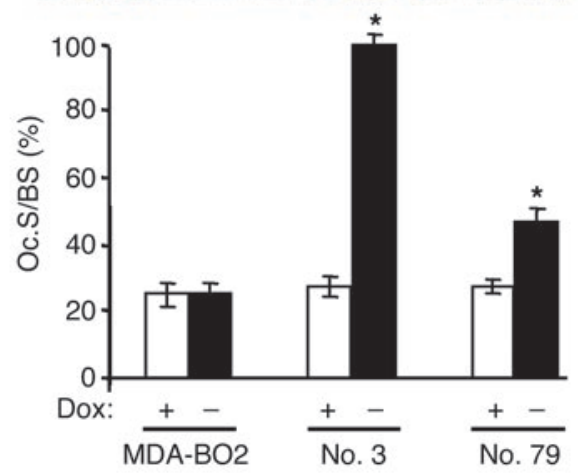

No. 3
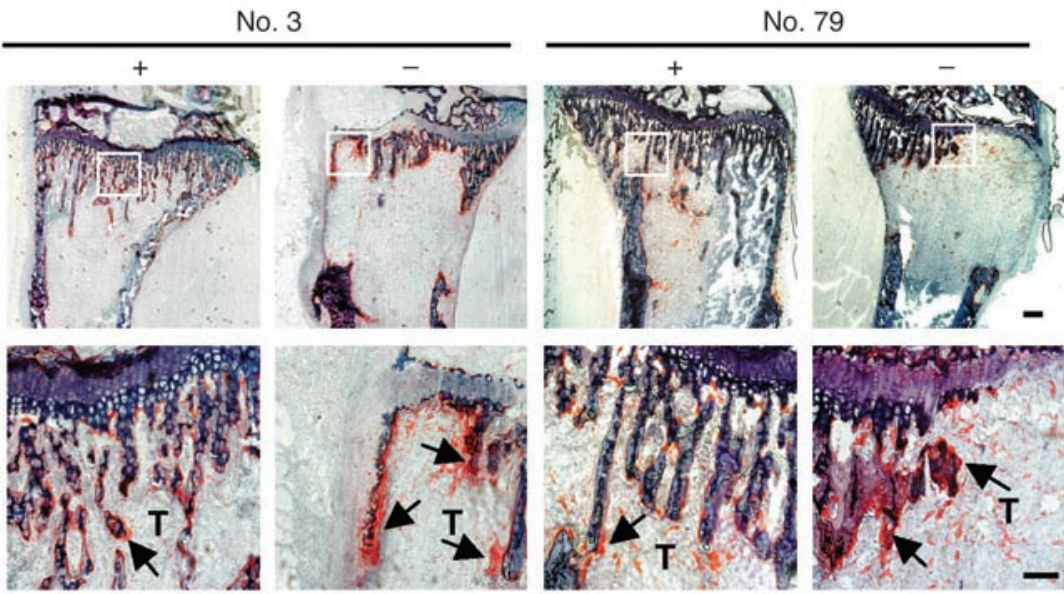

\section{Figure 9}

Effect of $\mathrm{LPA}_{1}$ overexpression in MDA-BO2 cells on osteoclast activity in vivo. (A) Animals fed without or with doxycycline were inoculated intravenously with MDA-BO2 or transfectants (clone no. 3 and clone no. 79 cells). Representative histological examination of TRAP-stained proximal tibia section from metastatic animals 30 days after tumor cell inoculation. Lower panels show magnified areas (white squares) from upper panels. Bone is stained in dark blue and osteoclasts are stained in red (arrows). Scale bar: $200 \mu \mathrm{m}$. (B) The Oc.S/BS ratio was quantified. Results are the mean \pm SD of $4-6$ animals per group. ${ }^{*} P<0.001$ doxycycline-free versus doxycycline-fed animals. 

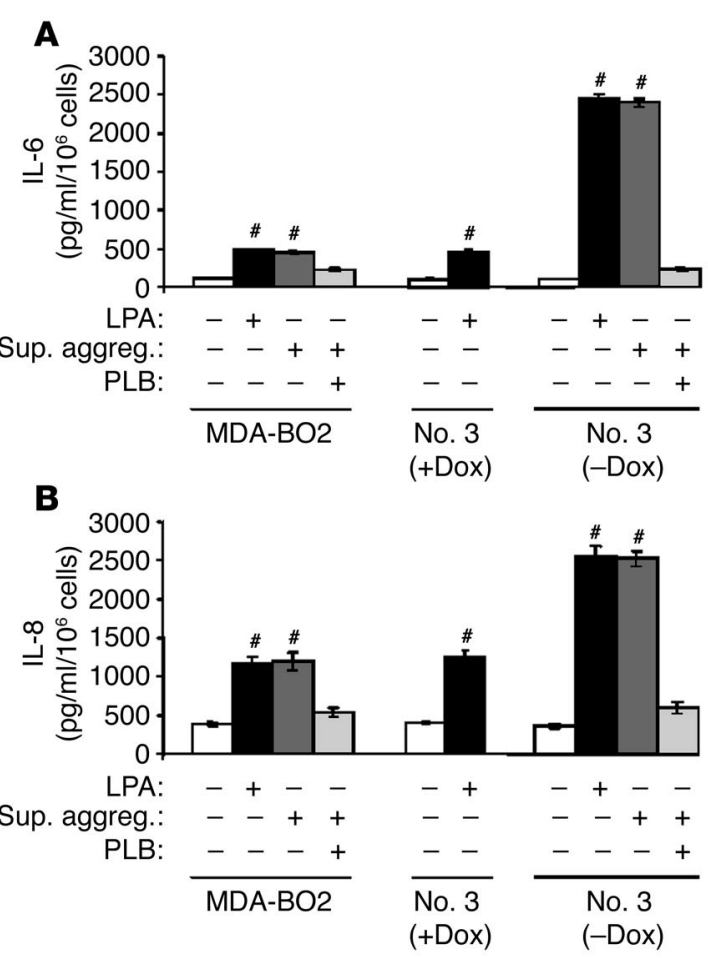

buffered saline) into the flank of nude mice that had been previously treated for 2 days with doxycycline. Seven days after tumor-cell inoculation, mice were randomized into 2 groups: 1 group received doxycycline for the duration of the experiment, whereas the other group did not. Tumor size was assessed by external measurement of the length (L) and width (W) of the tumors using a Vernier caliper. Tumor volume (V; expressed in $\mathrm{mm}^{3}$ ) was calculated using the following equation: $\mathrm{V}=\left(\mathrm{L} \times \mathrm{W}^{2}\right) / 2$.

Human studies. Studies involving primary breast tumors and platelet aggregations were performed according to the principles embodied in the Declaration of Helsinki. All human experiments were approved by the Experimental Review Board from the Laennec School of Medicine.

Reverse transcription, standard and quantitative PCR. Total RNA from cell lines and human breast tumors was extracted using Total RNA Isolation System (Promega). cDNA was synthesized using Moloney murine leukemia virus-1 (Promega). Primers for human $\mathrm{LPA}_{1}, \mathrm{LPA}_{2}$ (43), GAPDH (10), and ATX (44) were designed as described previously. $\mathrm{LPA}_{3}$ primers were designed from the Lpa3 gene (National Center for Biotechnology Information [NCBI] accession number AF127138) using nucleotides 738-756 as the forward primer and nucleotides $994-973$ as the reverse primer. Primers for hamster LPA receptors were designed from the NCBI nucleotide sequence database as follows: $\mathrm{LPA}_{1}$ (accession number AY522544),

\section{Figure 11}

Schematic representation of the LPA effects on progression of osteolytic bone metastases. Breast cancer cells produce factors (PTHrP, cytokines) that stimulate osteoclast-mediated bone resorption. In turn, bone resorption releases growth factors (IGFs, TGF- $\beta$ ) from the bone matrix that stimulate tumor growth and the production of PTHrP by tumor cells (16). This results in a vicious cycle, illustrated by dotted arrows. Bone-residing breast cancer cells also induce platelet aggregation and the release of LPA from activated platelets. Platelet-derived LPA then stimulates both tumor growth and the production of IL- 6 and IL-8 by tumor cells (black arrows), which in turn enhance bone resorption.

\section{Figure 10}

Effect of purified or platelet-derived LPA on the production of IL-6 and IL-8 by breast cancer cells. IL-6 (A) and IL-8 (B) were quantified using culture media from cells pretreated in the presence or absence of LPA, the supernatant of breast cancer cell-induced platelet aggregation, and PLB. Data are expressed as the mean \pm SD of 3 replicates and are representative of 2 separate experiments. ${ }^{\sharp} P<0.0001$ stimulated versus unstimulated cells.

nucleotides $147-169$ as the forward primer and nucleotides $342-323$ as the reverse primer; $\mathrm{LPA}_{2}$ (accession number AY522546), nucleotides 236-254 as the forward primer and nucleotides $518-499$ as the reverse primer; $\mathrm{LPA}_{3}$ (accession number AY522549), nucleotides 171-191 as the forward primer and nucleotides 353-334 as the reverse primer. GAPDH primers recognized GAPDH cDNA from both human and $\mathrm{CHO}$ cells. PCR reactions were run using a program consisting of 40 cycles of $95^{\circ} \mathrm{C}$ for $15 \mathrm{~s}$, $53^{\circ} \mathrm{C}$ for $30 \mathrm{~s}$, and $72^{\circ} \mathrm{C}$ for $20 \mathrm{~s}$ with a preincubation of $95^{\circ} \mathrm{C}$ for $2 \mathrm{~min}$. Products from standard PCR were separated by electrophoresis on a $2 \%$ agarose gel and then visualized with ethidium bromide under ultraviolet light. Human $\mathrm{LPA}_{1}, \mathrm{LPA}_{2}$, and $\mathrm{LPA}_{3} \mathrm{mRNAs}$ were quantified by real-time PCR using the Master SYBR Green I kit (Roche Diagnostics). Fluorescence was monitored and analyzed in a Light Cycler (Roche Diagnostics). The fluorescence data were quantitatively analyzed by using serial dilution of control samples included in each reaction to produce a standard curve. GAPDH mRNA expression was analyzed in parallel to confirm the use of equal amount of cDNAs in each reaction. Results are expressed as the percentage of gene expression in each cell line compared with that in the parental MDA-BO2 cells cultured in the absence of doxycycline.

Luciferase activity assay and flow cytometry. Luciferase activity was measured on cell lysates in accordance with the manufacturer's instructions (Promega). Prior to flow cytometry analysis, tumor cells were cultured in medium complemented with or left without doxycycline $(100 \mathrm{ng} / \mathrm{ml})$. Expression of HA- $\mathrm{LPA}_{1}$ at the cell surface was detected using a mouse anti-HA monoclonal antibody 12CA5 (Roche Diagnostics). Monoclonal antibody MOPC21 (Santa Cruz) was used as an isotypic negative control antibody.

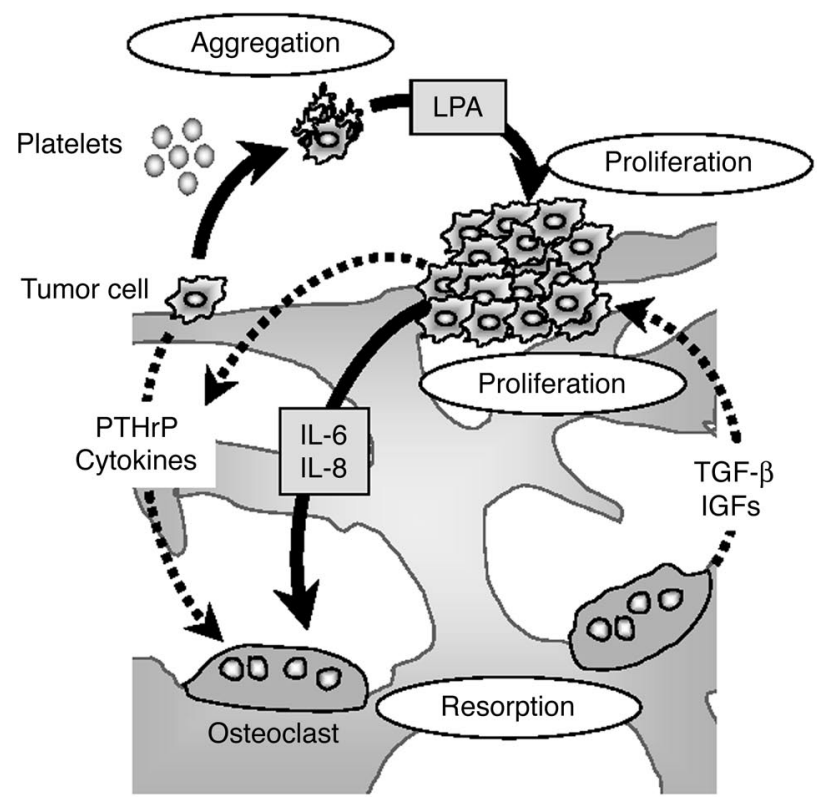


Bone histology. Hind limbs from animals were fixed and embedded in methylmethacrylate. Seven-micrometer sections of undecalcified long bones were stained with Goldner's trichrome, and histological analyses were performed on longitudinal medial sections of tibial metaphysis using the computerized image analysis system Visiolab 2000 (Biocom), as previously described $(26,39)$. The in situ detection of osteoclasts was carried out on metastatic bone tissue sections stained for tartarate-resistant acid phosphatase (TRAP) activity using a commercial kit (Sigma-Aldrich). The resorption surface (Oc.S/BS) was calculated as the ratio of the TRAP-positive trabecular bone surface (Oc.S) to the total trabecular bone surface (BS) using a semiautomatic analyzer (Ibas; Leica).

Immunohistochemistry. Bone tissue specimens and tumor xenografts were fixed and then embedded as previously described (39). Six-micrometer tissue sections were then subjected to immunohistochemistry using a mouse anti-human Ki67 monoclonal antibody that specifically recognizes proliferative cells (DakoCytomation). The mitotic index was calculated as the ratio of the number of nuclei immunostained for Ki-67 to the total number of nuclei per field and expressed as the percentage of Ki-67-positive nuclei.

Platelet aggregation. Blood samples were taken from healthy volunteers. Platelet aggregation experiments were performed using washed platelets from human blood freshly collected in citrate as an anticoagulant, as previously described (38). Breast or ovarian cancer cells $\left(4 \times 10^{6}\right.$ cells) previously cultured in the absence or in the presence of doxycycline were added to washed human platelets $\left(4 \times 10^{5}\right.$ platelets $\left./ \mu \mathrm{l}\right)$ in a final volume of $400 \mu \mathrm{l}$ under stirring conditions at $37^{\circ} \mathrm{C}$. Platelet aggregation was monitored over the time as the percentage of light transmission.

Cell proliferation assay. Experiments were carried out as previously described (45). Briefly, quiescent tumor cells $\left(5 \times 10^{3}\right.$ cells per well) cultured in 96-well tissue culture plates (BD Biosciences) in medium containing $0.1 \%(\mathrm{w} / \mathrm{v})$ BSA fatty acid-free supplemented with or left without doxycycline $(100 \mathrm{ng} / \mathrm{ml})$ were treated overnight in the presence or absence of increasing 1-oleoyl LPA concentrations or with the supernatant of plate- let aggregates, and in the presence or absence of PLB (Sigma), and then pulsed with $\left[{ }^{3} \mathrm{H}\right]$-thymidine for the last 8 hours.

Quantification of LPA and lyso-PLD activity. LPA was butanol-extracted from conditioned medium or citrated mouse plasma and quantified using a radioenzymatic assay as described previously (46). In these conditions, minimal detection of LPA was $0.2 \mathrm{pmol}$ (46). Lyso-PLD activity was measured by conversion of radiolabeled LPC into radiolabeled LPA as described previously (44).

Measurement of IL- 6 and IL-8 production by ELISA. Conditioned media of cell lines treated with LPA or left untreated or the supernatants of tumor cell-induced platelet aggregates were collected and analyzed for IL- 6 and IL- 8 production by ELISA using the human IL- 6 or IL-8 Module Set Bender MedSystems (TEBU). Concentrations of IL- 6 and IL- 8 were expressed in $\mathrm{pg} / \mathrm{ml}$ per $10^{6}$ cells.

Statistical analysis. Data were analyzed with the Stat-View 5.0 software using unpaired Student's $t$ test. $P$ values less than 0.05 were considered statistically significant.

\section{Acknowledgments}

This study was supported by grants from the INSERM (to O. Peyruchaud and P. Clézardin), the European Commission (to P. Clézardin, contract LSHC-CT-2004-503049), and the Comité Départemental de la Loire de la Ligue Nationale contre le Cancer (to O. Peyruchaud). A. Boucharaba is a recipient of a fellowship from the French Ministry for Research.

Received for publication May 11, 2004, and accepted in revised form October 19, 2004.

Address correspondence to: Olivier Peyruchaud, INSERM U403, Université Claude Bernard Lyon 1, IFR-62, Faculté de Médecine Laennec, rue Guillaume Paradin, 69372 Lyon Cedex 08, France. Phone: 33-47878-57-38; Fax: 33-478-77-86-63; E-mail: peyruchaud@lyon.inserm.fr.
1. An, S., Dickens, M.A., Bleu, T., Hallmark, O.G., and Goetzl, E.J. 1997. Molecular cloning of the human Edg2 protein and its identification as a functional cellular receptor for lysophosphatidic acid. Biochem. Biophys. Res. Commun. 231:619-622.

2. An, S., Bleu, T., Hallmark, O.G., and Goetzl, E.J. 1998. Characterization of a novel subtype of human $\mathrm{G}$ protein-coupled receptor for lysophosphatidic acid. J. Biol. Chem. 273:7906-7910.

3. Bandoh, K., et al. 1999. Molecular cloning and characterization of a novel human G-protein-coupled receptor, EDG7, for lysophosphatidic acid J. Biol. Chem. 274:27776-27785.

4. Noguchi, K., Ishii, S., and Shimizu, T. 2003. Identification of $\mathrm{p} 2 \mathrm{y} 9 / \mathrm{GPR} 23$ as a Novel G Proteincoupled receptor for lysophosphatidic acid, structurally distant from the Edg family. J. Biol. Chem. 278:25600-25606

5. McIntyre, T.M., et al. 2003. Identification of an intracellular receptor for lysophosphatidic acid (LPA): LPA is a transcellular PPARgamma agonist. Proc. Natl. Acad. Sci. U. S. A. 100:131-136.

6. Moolenaar, W.H. 2000. Development of our current understanding of bioactive lysophospholipids. Ann. N. Y. Acad. Sci. 905:1-10.

7. Mills, G.B., and Moolenaar, W.H. 2003. The emerging role of lysophosphatidic acid in cancer. Nat. Rev. Cancer. 3:582-591.

8. Xu, Y., et al. 1998. Lysophosphatidic acid as a potential biomarker for ovarian and other gynecologic cancers. JAMA. 280:719-723.

9. Fang, X., et al. 2002. Lysophosphatidic acid is a bioactive mediator in ovarian cancer. Biochim. Biophys. Acta. 1582:257-264
10. Goetzl, E.J., et al. 1999. Distinctive expression and functions of the type 4 endothelial differentiation gene-encoded $G$ protein-coupled receptor for lysophosphatidic acid in ovarian cancer. Cancer Res. 59:5370-5375.

11. Hu, Y.L., et al. 2001. Lysophosphatidic acid induction of vascular endothelial growth factor expression in human ovarian cancer cells. J. Natl. Cancer Inst. 93:762-768.

12. Goetzl, E.J., Dolezalova, H., Kong, Y., and Zeng, L. 1999. Dual mechanisms for lysophospholipid induction of proliferation of human breast carcinoma cells. Cancer Res. 59:4732-4737.

13. Yang, S.Y., et al. 2002. Expression of autotaxin (NPP-2) is closely linked to invasiveness of breast cancer cells. Clin. Exp. Metastasis. 19:603-608.

14. Body, J.J. 1992. Metastatic bone disease: clinical and therapeutic aspects. Bone. 13:S57-S62.

15. Guise, T.A., and Mundy, G.R. 1998. Cancer and bone. Endocr. Rev. 19:18-54.

16. Mundy, G.R. 2002. Metastasis to bone: causes, consequences and therapeutic opportunities. Nat. Rev. Cancer. 2:584-593.

17. Pluijm, G., Lowik, C., and Papapoulos, S. 2000. Tumour progression and angiogenesis in bone metastasis from breast cancer: new approaches to an old problem. Cancer Treat. Rev. 26:11-27.

18. Pickering, L.M., and Mansi, J.L. 2002. The role of bisphosphonates in breast cancer management: review article. Curr. Med. Res. Opin. 18:284-295.

19. Eichholtz, T., Jalink, K., Fahrenfort, I., and Moolenaar, W.H. 1993. The bioactive phospholipid lysophosphatidic acid is released from activated platelets. Biochem. J. 291:677-680.
20. Aoki, J., et al. 2002. Serum lysophosphatidic acid is produced through diverse phospholipase pathways. J. Biol. Chem. 277:48737-48744.

21. Bakewell, S.J., et al. 2003. Platelet and osteoclast beta3 integrins are critical for bone metastasis. Proc. Natl. Acad. Sci. U. S. A. 100:14205-14210.

22. Amirkhosravi, A., et al. 2003. Inhibition of tumor cell-induced platelet aggregation and lung metastasis by the oral GPIIb/IIIa antagonist XV454. Thromb. Haemost. 90:549-554.

23. Fang, X., et al. 2004. Mechanisms for lysophosphatidic acid-induced cytokine production in ovarian cancer cells. J. Biol. Chem. 279:9653-9661.

24. Bandoh, K., et al. 2000. Lysophosphatidic acid (LPA) receptors of the EDG family are differentially activated by 95LPA species. Structure-activity relationship of cloned LPA receptors. FEBS Lett. 478:159-165.

25. Peyruchaud, O., et al. 2001. Early detection of bone metastases in a murine model using fluorescent human breast cancer cells: application to the use of the bisphosphonate zoledronic acid in the treatment of osteolytic lesions. J. Bone Miner. Res. 16:2027-2034

26. Pecheur, I., et al. 2002. Integrin alpha(v)beta3 expression confers on tumor cells a greater propensity to metastasize to bone. FASEB J. 16:1266-1268.

27. Camerer, E., et al. 2004. Platelet, protease-activated receptors, and fibrinogen in hematogenous metastasis. Blood. 104:397-401.

28. Mundy, G., Oyojobi, B., Taraianedes, K., Dallas, S., and Chen, D. 2001. Cytokines and bone remodeling. Academic Press. London, United Kingdom. 373-403. 
29. de la Mata, J., et al. 1995. Interleukin-6 enhances hypercalcemia and bone resorption mediated by parathyroid hormone-related protein in vivo. J. Clin. Invest. 95:2846-2852.

30. Bendre, M.S., et al. 2002. Expression of interleukin 8 and not parathyroid hormone-related protein by human breast cancer cells correlates with bone metastasis in vivo. Cancer Res. 62:5571-5579.

31. Xu, Y., Fang, X.J., Casey, G., and Mills, G.B. 1995. Lysophospholipids activate ovarian and breast cancer cells. Biochem. J. 309:933-940.

32. Hama, K., et al. 2004. Lysophosphatidic acid and autotaxin stimulate cell motility of neoplastic and non-neoplastic cells through LPA1. J. Biol. Chem. 279:17634-17639.

33. Umezu-Goto, M., et al. 2002. Autotaxin has lysophospholipase D activity leading to tumor cell growth and motility by lysophosphatidic acid production. J. Cell. Biol. 158:227-233.

34. Karpatkin, S., Pearlstein, E., Ambrogio, C., and Coller, B.S. 1988. Role of adhesive proteins in platelet tumor interaction in vitro and metastasis formation in vivo. J. Clin. Invest. 81:1012-1019.

35. Felding-Habermann, B., et al. 2001. Integrin activa- tion controls metastasis in human breast cancer. Proc. Natl. Acad. Sci. U. S. A. 98:1853-1858.

36. Carmeliet, P., and Jain, R.K. 2000. Angiogenesis in cancer and other diseases. Nature. 407:249-257.

37. Trikha, M., and Nakada, M.T. 2002. Platelets and cancer: implications for antiangiogenic therapy. Semin. Thromb. Hemost. 28:39-44.

38. Belloc, C., et al. 1995. The effect of platelets on invasiveness and protease production of human mammary tumor cells. Int. J. Cancer. 60:413-417.

39. Peyruchaud, O., Serre, C.-M., NicAmhlaoibh, R., Fournier, P., and Clezardin, P. 2003. Angiostatin inhibits bone metastasis formation in nude mice through a direct anti-osteoclastic activity. J. Biol. Chem. 278:45826-45832.

40. Tokumura, A., Fukuzawa, K., Isobe, J., and Tsukatani, H. 1981. Lysophosphatidic acid-induced aggregation of human and feline platelets: structure-activity relationship. Biochem. Biophys. Res. Commun. 99:391-398.

41. Martin, T.J. 2002. Manipulating the environment of cancer cells in bone: a novel therapeutic approach. J. Clin. Invest. 110:1399-1401. doi:10.1172/ JCI200217124.
42. Peyruchaud, O., and Mosher, D.F. 2000. Differential stimulation of signaling pathways initiated by Edg- 2 in response to lysophosphatidic acid or sphingosine-1-phosphate. Cell. Mol. Life Sci. 57:1109-1116

43. Zhang, Q., Peyruchaud, O., French, K.J., Magnusson, M.K., and Mosher, D.F. 1999. Sphingosine 1phosphate stimulates fibronectin matrix assembly through a Rho-dependent signal pathway. Blood. 93:2984-2990.

44. Ferry, G., et al. 2003. Autotaxin is released from adipocytes, catalyzes lysophosphatidic acid synthesis, and activates preadipocyte proliferation. Up-regulated expression with adipocyte differentiation and obesity. J. Biol. Chem. 278:18162-18169.

45. Abbadia, Z., Clezardin, P., Serre, C.M., Amiral, J., and Delmas, P.D. 1993. Thrombospondin (TSP1) mediates in vitro proliferation of human MG-63 osteoblastic cells induced by alpha-thrombin. FEBS Lett. 329:341-346.

46. Saulnier-Blache, J.S., Girard, A., Simon, M.F., Lafontan, M., and Valet, P. 2000. A simple and highly sensitive radioenzymatic assay for lysophosphatidic acid quantification. J. Lipid Res. 41:1947-1951. 